\title{
Nest Site Selection of Some Birds Species Breeding in Zalingei Area-Darfur, Sudan
}

\author{
Abdallah Mohamed Abdallah Ahmed Korssi ${ }^{1}$, Dawi Musa Hamad ${ }^{2}$ \\ ${ }^{1}$ Department of Wildlife, University of Zalingei, Sudan \\ ${ }^{2}$ Department of Zoology University of Khartoum - Sudan
}

\begin{abstract}
This study was conducted in Zalingei area in two seasons 2013 and 2014, to study the Nest sites selection to some breeding species. Descriptive analysis methods was used, The data was collected on nests location, Nest height from ground, distance between the neighbor nests and tree height from ground were taken. The metric tape (50m) was used to measure the canopy cover (the measure of percentage of tree canopy near to the nest, four readings; one on each cardinal direction (North, East, South and West)[21].The results, showed that Black-headed, Weaver Ploceuscucullatus built large numbers of nests per tree 81.5 nests/tree, and highest mean nest height $13.36 m$, whereas the Cliff chat Thamnolaeacinnamomeiventris had the lowest 1.28m.The Cliff chat Thamnolaeacinnamomeiventris had the longer distance between nests than that of other eight species in the study area. The Marabou Stork Leptoptiloscrumeniferus built their nests on the highest tree $(16.53 \mathrm{~m})$. The result, showed very high significant difference between canopy cover of the trees on which bird nests were observed $(p=3.805 E-71)$. The study was recommended to addition study in nest site selection for most breeding species in Zalingei area.
\end{abstract}

Keywords: Nest site, breeding species, Birds of Zalingei, Korssi

\section{Introduction}

Selection favors individuals that choose resources that enhance breeding success, but limited availability of such resources can limit the number of individuals that breed $[22,5]$.

According to [23] quality of nest sites can be affected by micro-climate, food availability, and nest predation. Nest predation is usually the primary source of nest mortality for open nesting birds $[18,20]$. As a result, choice of nest sites with reduced risk of nest predation and more foraging substrates should be favored. Probability of predation may decrease with increasing abundance of potential nest sites (snags and cavities), because predators must search more empty sites to find an occupied site $[6,17]$.

Predation may also increase in lower nests [20]. Most predators are small mammals and tree-climbing snakes [20]. These predators may be able to reach lower nests more easily and provide parent birds less time to detect and perhaps dislodge climbing nest predators [20].

Birds are not distributed at random among habitats [7]. Many studies have found differences between the habitat used for nesting and the available nesting habitat [18]. Currently, it is assumed that these patterns of habitat use are the result of the process of natural selection acting on a long-term scale, because nest site selection may have a direct influence on individual fitness. Most studies of nest site selection have assessed whether there are differences between the general habitat and the portion of the habitat used for nesting, and whether habitat characteristics of successful and unsuccessful nest sites [11]. Nest predation is usually the main cause of egg and chick mortality [19]. It has been found in some species that the probability of nest predation varies with the species of plant that supports the nest and the location of the nest inside the plant or with the features of the immediate area around the nest. Thus, it is widely believed that nest site selection in birds may have evolved mainly as an adaptive response against nest predators $[2,11]$.

[12] recorded that some of our studied species may be able to maintain relatively high nesting success by adjusting breeding habitat selection or breeding territory or nest site selection (within patch scale) to avoid areas with more predators (e.g., Bewick's Wrens, Winter Wrens, and Song Sparrows).

Increased numbers are correlated with increased efficiency of group defense ( e.g. Gulls, Terns, Blackbirds and Swallows [13]. There is a decreased probability of predation on centrally placed nest sites, i.e. the selfish-herd phenomenon (e.g. Penguins, Egrets, Gulls, [25]. No one of these adaptations, however, is likely to protect a colonial species against all of its potential predators. For example, nesting on islands may protect seabirds against mammalian predators but not against avian predators [14]. Increased group defense may work well against avian predators and small diurnal mammals (Gulls: [13], but it is usually ineffective in deterring large mammals, nocturnal snakes, and some large or socially attacking avian predators $[9,13]$.

[14]mention that the nest height was positively correlated with tree height, at least marginally so. Tree height explains $34 \%$ of the variation in nest height[25]. However, nest height was not related to tree type or circumference. Nor were trees with and without nests significantly different in height or circumference [25]. Nest trees were adjacent to significantly larger canopy openings required to access the nest site [25].

\section{Materials and methods}

\subsection{Study Area}

Zalingei area lies in the western slopes of Jebel Marra in the poor savanna zone between latitudes $12^{\circ} 30$ and $13^{\circ} 30$ North, and longitudes $22^{\circ} 20$ and $23^{\circ} 45$ East according to 


\section{International Journal of Science and Research (IJSR) \\ ISSN (Online): 2319-7064 \\ Index Copernicus Value (2013): 6.14 | Impact Factor (2015): 6.391}

Hunting Technical Services, [10]. The area is not traversed by any perennial river, only seasonal streams, small lakes and spring. The longest seasonal stream is WadiAzoum originating from Jebel Marra. Rain-fed crops of Sorghum and Millet are grown. Other human activities include vegetables and orchards growing. The altitude ranges from 500 to 1200 meters above sea level. The annual rainfall varies between 350 and 750 millimeters. The mean average temperature ranges between $20^{\circ} \mathrm{C}$ and $30^{\circ} \mathrm{c}$. The plains are widely utilized for rain-fed cultivation of cereals as Sorghum spp.(Dura), Milletand Oryzaspp(Rice). The plains are also important as rangeland for livestock and it's woodland is important habitats for birds[1].

Zalingei area is mountainous in nature and according to [1, $26,27]$ is covered with various species of trees, shrubs, grasses and herbaceous species (table,I). The flatlands and mountain slopes are traversed by many seasonal Wadis and Khors coming from the higher reaches of Jebel Marra (WadiAzoum, WadiAreebou). These pass through the Zalingei area, but in dry season they leave many permanent water pools in the Wadi,[10]. These wetlands are important habitats for migratory and resident birds, especially water birds, for drinking, nesting, resting and feeding.

\subsection{Data Collection}

The sites were visited every month of study period to record the breeding activities such as; nesting, mating, eggs and young.

The breeding activities in the study area was conducted in the mornings and in the afternoons to locate nesting attempts on all study areas during the two years April to November 2013( first season) - April to November 2014 (second season). Some data were collected on nests throughout the study period.

Nest height from ground, nearest distance between the neighbor nests and tree heights from ground were taken by using Blume-liss (Blume-liss is trigonometric used to measure the tree height ) [16] (plate,1). The metric tape $(50 \mathrm{~m})$ was used to measure the canopy cover (the measure of percentage of tree canopy near to the nest, four readings; one on each cardinal direction (North, East, South and West)[21]. The replication of ten trees for each nine species were calculatedThe variables measured for the nests and nest-tree was statistically evaluated usingPAleontologicalSTatistics (PAST).

\subsection{Data analysis}

The percent of canopy cover was calculated as the average of the $\%$ of filled squares $(x)$ of the 4 cardinal directions:

$\%$ Canopy Cover $=\left[\frac{\left(\mathrm{X}_{\Xi}+\mathrm{X}_{\mathrm{N}}+\mathrm{X}_{\mathrm{S}}+\mathrm{X}_{\mathrm{W}}\right)}{4}\right]$

The variables measured for the nests and nest-tree was statistically evaluated using Paleontological Statistics (PAST)Version 2.17 to Analysis of Variation (ANOVA) One-Way and Tukey`s pairwise comparisons Q/p(same) Oyvind $[15,18]$. The replication of ten trees for each nine species were calculated. Means figures were obtained using Excel.

\section{Results}

\subsection{Nest Number}

Black-headed, WeaverPloceuscucullatusbuilt large numbers of nests per tree 81.5 nests/tree; it had the highest nest number of all the other eight species in the study area, followed by Cattle Egret, Bubulcus ibis 55.23 nest/tree.

The Abdim's Stork Ciconiaabdimii built lowest nests numbers 2.2 nest/tree (Fig, 1). The result, showed, very highly significant difference between nest number per tree of the nine birds species in Zalingei area $(p=1.9 \mathrm{E}-75)$. The source of these very highly significant difference was the differentiation in nest number per tree between four species as: Cattle Egret, Bubulcus ibis, Black headed Heron Ardeamelanocephala,

Black-headed,

WeaverPloceuscucullatus, Cut-throat Finch, Amadinafasciata, compared with all other five species as: Cliff chat, Thamnolaeacinnamomeiventri Sacred Ibis Threskiornisaethiopicus, Abdim's StorkCiconiaabdimii, Marabou Stork Leptoptiloscrumeniferus, Glossy Starling Lamprotornischloropterus. The differences in nest number per tree between the above four species scored the probability $(p=0.00013)$ in comparison between them. However there was no significant difference in nest number per tree between these following species, these shown in comparison between Cliff Chat,ThamnolaeacinnamomeiventriandSacred

Ibis,Threskiornisaethiopicus $\quad(p=0.1796), \quad$ Cliff chat,Thamnolaeacinnamomeiventri and Abdim's Stork $\begin{array}{llll}\text { Ciconiaabdimii, } & (p= & 1) . & \text { Cliff }\end{array}$ chat,Thamnolaeacinnamomeiventri and Marabou Stork,Leptoptiloscrumeniferus $\quad(p=0.9884) . \quad$ Cliff chat,Thamnolaeacinnamomeiventriand Short-tailed Glossy Starling,Lamprotornischloropterus $(p=1)$. Between nest number of Sacred Ibis,Threskiornisaethiopicusand Abdim's Stork Ciconiaabdimii $\quad(p=0.1091) . \quad$ Sacred Ibis,Threskiornisaethiopicusand Marabou Stork,Leptoptiloscrumeniferus $\quad(p=0.7457) . \quad$ Sacred Ibis,Threskiornisaethiopicusand Short-tailed Glossy Starling,Lamprotornischloropterus $(p=0.2425)$. Also no difference in nest number per tree between Abdim's Stork Ciconiaabdimiiand Marabou Stork,Leptoptiloscrumeniferus $(p=0.9582)$,Abdim's Stork CiconiaabdimiiandShort-tailed Glossy Starling,Lamprotornischloropterus $(p=1)$. No difference in nest number per tree between; Marabou Stork,Leptoptiloscrumeniferus andShort-tailed Glossy Starling,Lamprotornischloropterus $(p=0.9962)$ (figure,1).

\subsection{Nest Height}

The mean nest heights of 90 nests were analyzed and showed that the Black headed Heron Ardeamelanocephalahad the highest mean nest height $13.36 \mathrm{~m}$, whereas the Cliff chat Thamnolaeacinnamomeiventris had the lowest $1.28 \mathrm{~m}$ (Fig, 2).The nest heights (from the ground) of nine birds species showed very high significant difference $(p=5.901 E-41)$. The source of this differences is between species that built high nests from ground as Cattle Egret, Bubulcus ibis, Black- 


\section{International Journal of Science and Research (IJSR) \\ ISSN (Online): 2319-7064 \\ Index Copernicus Value (2013): 6.14 | Impact Factor (2015): 6.391}

headed, WeaverPloceuscucullatus, Cut-throat Finch,Amadinafasciata, Sacred Ibis,Threskiornisaethiopicus, Abdim's Stork Ciconiaabdimii, Short-tailed Glossy Starling,Lamprotornischloropterus $(p=0.00013)$ and all other species.

\subsection{Distance between the nearest Nests}

The Cliff chatThamnolaeacinnamomeiventris had the longer distance between nests than that of other eight species in the study area. Short-tailed Glossy Starling Lamprotornischloropterus built nests with short distance (fig,1).The result, showed very high significant difference between nearest neighbor distance in the nine birds species $(p=1.136 \mathrm{E}-05)$. The source of these differences were between; Cliff chat, Thamnolaeacinnamomeiventri compared with all other eight species in the study area, while nosignificant difference between nearest neighbor distance in the other eight birds species which were builts lowest nearest neighbor distance between the nests.

3.4 Mean tree height on which nine birds species built their nests

The results showed that the Marabou Stork Leptoptiloscrumeniferus built their nests on the highest tree $(16.53 \mathrm{~m})$ followed by Cattle Egret Bubulcus ibis $(16 \mathrm{~m})$ andBlack-headed WeaverPloceuscucullatus $(15.89 \mathrm{~m})$. The Cliff chat Thamnolaeacinnamomeiventris built their nests in lowest tree than all other eight species $(2.7 \mathrm{~m})$ (fig,2). The result, showed very highly significantly different between trees height of nine birds species $(\mathrm{p}=7.355 \mathrm{E}-19)$. The source of these differences were between the birds species were selected highest tree height to build their nests compared with birds species were selected lowest tree height to build their nests, however; no significant difference in nest height between birds species were selected lowest tree height to build their nests.

\subsection{Canopy cover of the trees on which bird nests:}

Black headed HeronArdeamelanocephala, Cattle EgretBubulcus ibis andMarabou StorkLeptoptiloscrumeniferus built their nest in tree with a big canopy cover. Sacred IbisThreskiornisaethiopicus, Abdim's StorkCiconiaabdimii, and Black-headed WeaverPloceuscucullatuswere choosing the tree that had medium canopy cover.

The Cliff ChatThamnolaeacinnamomeiventris, short-tailed Glossy StarlingLamprotornischloropterus andCut-throat FinchAmadinafasciata placed their nests in smaller canopy cover. The result, showed very high significant difference between canopy cover of the trees on which bird nests were observed $(p=3.805 \mathrm{E}-71)$. The source of these significant differences were between; Cattle Egret Bubulcus ibis, Blackheaded WeaverPloceuscucullatuscompared with all other species except betweenCattle Egret Bubulcus ibis and Black headed HeronArdeamelanocephala $(\mathrm{p}=0.86)$, Cattle Egret Bubulcus ibis and Marabou Stork Leptoptilos $(\mathrm{p}=0.9351)$, Black headed HeronArdeamelanocephalaandMarabou Stork Leptoptilos ( $\mathrm{p}=0.1437$ ), Cut-throat Finch,Amadinafasciat and Abdim's Stork Ciconiaabdimii $(p=1)$ werenot significant difference in nest height (figure,1).

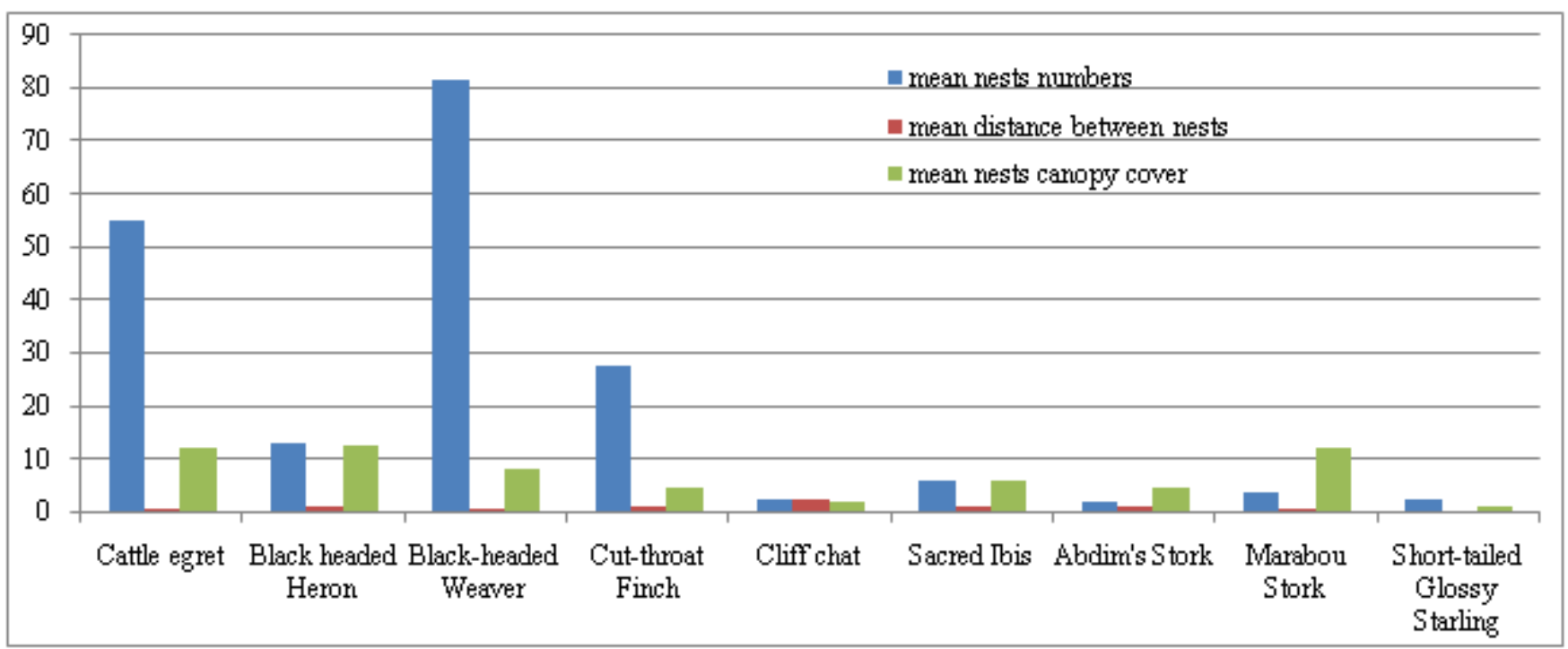

Figure 1: Mean nest number and nearest distance between nests compared with mean tree canopy cover in Zalingei area during 2013 and 2014 
International Journal of Science and Research (IJSR)

ISSN (Online): 2319-7064

Index Copernicus Value (2013): 6.14 | Impact Factor (2015): 6.391

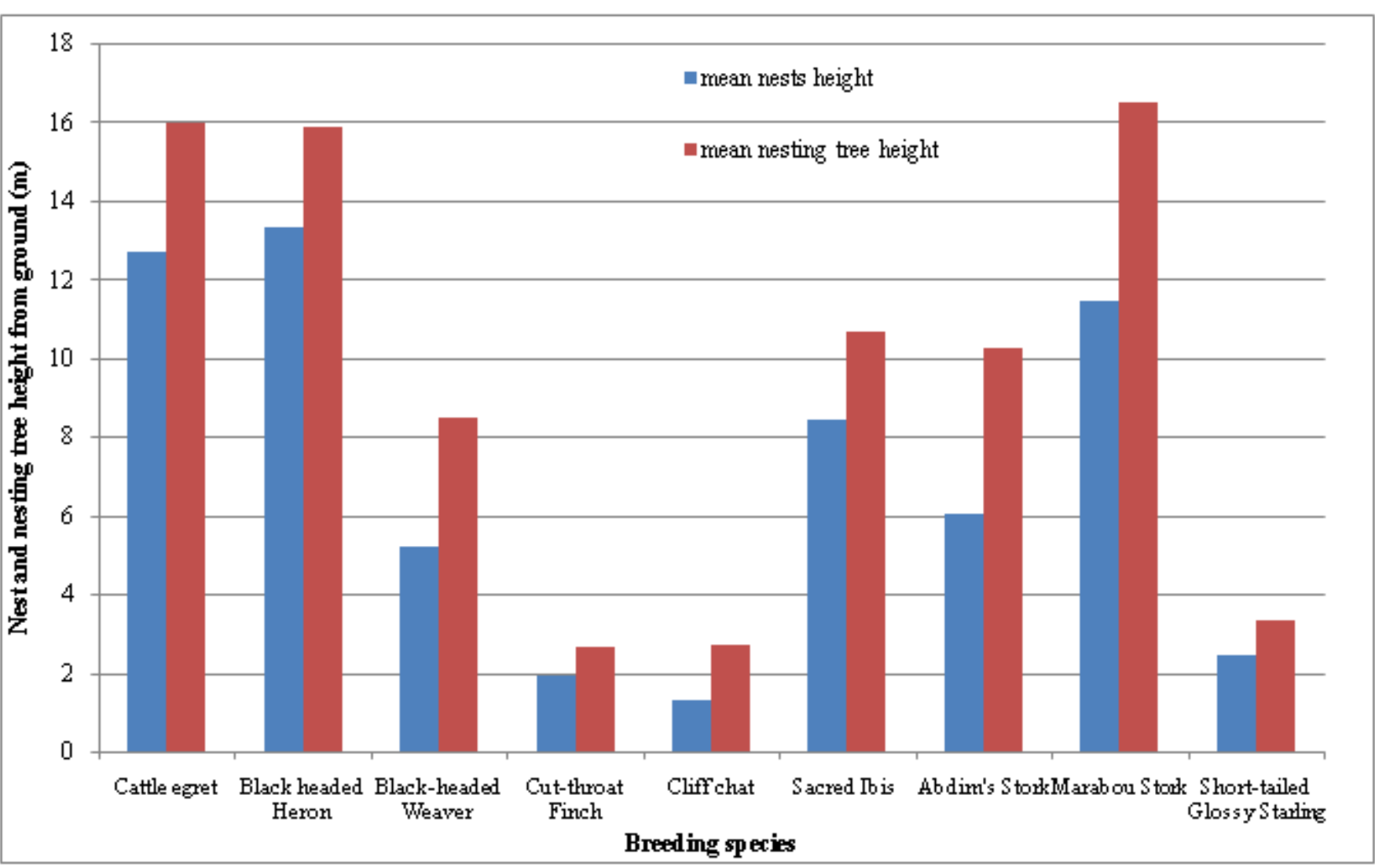

Figure 2: Mean height of nest and nesting tree in Zalingei area during 2013 and 2014.

\section{Discussion}

\subsection{Nest number}

The results showed very high significant difference between nest numbers per tree of the nine birds species in Zalingei area $(\mathrm{p}=1.9 \mathrm{E}-75)$.

The Black-headed Village Weaver Ploceuscucullatus built more number of nests per tree compared with all other species. This is because it was a highly colonial species. Marabou StorkLeptoptiloscrumeniferus,Sacred Ibis Threskiornisaethiopicu, Abdim's StorkCiconiaabdimiiand short-tailed Glossy StarlingLamprotornischloropterus built the lowest number of nests per tree. Abdim's StorkCiconiaabdimiibuilt their nests in the trees inside towns and villages. Short-tailed Glossy StarlingLamprotornischloropterus built big nests close to water and aquacultural land near to human activities to provied foods for chicks and protection from predators. $[3,12,18]$ believed that the a big number of nests become target to the predators. But they associate with other birds species during breeding season to gain protective benefits accordingly.

\subsection{Nest height}

The results showed that Black headed Heron Ardeamelanocephalahad the highest mean nest height, followed by Cattle EgretBubulcus ibis, Sacred IbisThreskiornisaethiopicus, Abdim's StorkCiconiaabdimii and Marabou StorkLeptoptiloscrumeniferus. This is because they had open flat nest and being high in tree provided protection against predators. Whereas, the Cliff
ChatThamnolaeacinnamomeiventris and Black-headed Weaver Ploceuscucullatus, had low nest heights. Blackheaded Weaver Ploceuscucullatus built their nests at the tip of the tree branches and on trees over water, which make them difficult for predators to get to. As for Cliff ChatThamnolaeacinnamomeiventristheir nests had the lowest height and build inside trees so it is difficult to find. The nest heights (from the ground) of nine birds species showed very high significant difference $(\mathrm{p}=5.901 \mathrm{E}-41)$.

\subsection{The nearest Distance between the nests:}

In this study the Cliff ChatThamnolaeacinnamomeiventris had the longest nearest distance between their nests compare to that of other eight species. This is because Cliff ChatThamnolaeacinnamomeiventris built few number of nest per tree. Short-tailed Glossy Starling Lamprotornischloropterusbuilt nests with low nearest neighbour nest distance, this is because it built nests like one nest in looking.

However, six species: Short-tailed Glossy Starling Lamprotornischloropterusand Black-headed WeaverPloceuscucullatus, Sacred IbisThreskiornisaethiopicusandAbdim's

StorkCiconiaabdimii, $\quad$ Marabou Stork Leptoptiloscrumeniferusand Cattle EgretBubulcus ibis built nests with low nearest neighbour nest distance, because it was colonial species and shared the same tree, with other species to protect their chicks from predators.

The results showed very high significant difference between nearest neighbor distance in the nine birds species ( $p=1.136 \mathrm{E}-05)$, due to colonial habits of some species. The colonial species built nests with low nearest neighbor 


\section{International Journal of Science and Research (IJSR) \\ ISSN (Online): 2319-7064}

Index Copernicus Value (2013): 6.14 | Impact Factor (2015): 6.391

distance because the site of their nest provide protection against predators. While non-colonials species like Cliff Chat Thamnolaeacinnamomeiventris built nests with long nearest neighbor distance since they built few nests per tree. [12] mentioned that birds species may prefere long trees to build their nests, so as to protect their offspring from predators.

\subsection{Tree height}

The results showed significant difference between trees height of nine birds species. The Marabou Stork Leptoptiloscrumeniferus followed by Cattle egret Bubulcus ibis built their flat form nests on the highest tree to avoid the small predators, for this reason they builts their nests on HarazFidherbiaalbida tree which was the highest tree in the study area. The Cliff chat Thamnolaeacinnamomeiventris built their nests in lowest tree than all other eight species and nests built in midde tree branchs as Heglig, Balanitesaegyptiaca.[25] believed that a decreased probability of predation on centrally placed nest sites.

\subsection{Canopy cover}

The results showed that Black headed HeronArdeamelanocephala, Cattle egretBubulcus ibis andMarabou StorkLeptoptiloscrumeniferus preferred to build their nests in trees with a big canopy cover, this is may be the reason Marabou StorkLeptoptiloscrumeniferushad a big size and heavy body, while the other two species were more colonial species, for that reasons they choose larger canopy cover.[8] mentioned that larger numbers of birds in colonis are more efficient at detecting predators

The Sacred IbisThreskiornisaethiopicus, Abdim's StorkCiconiaabdimii, Black-headed WeaverPloceuscucullatuspreferred the tree that had a medium canopy cover because they built their nests on the trees near roads, in hospitals, markets and houses.

The Cliff ChatThamnolaeacinnamomeiventris, Short-tailed Glossy StarlingLamprotornischloropterus andCut-throat FinchAmadinafasciatpreferred to place their nests in tree that had smaller canopy cover, because they do not associate with other birds.

The results showed very high significant difference between canopy cover of nine bird species $(p=3.805 \mathrm{E}-71)$, due to their colonial habit, body size and body weights. If the Marabou StorkLeptoptiloscrumeniferus build their nests on small canopy cover; this may lead to breaking (collapsing) of the branches.

\section{References}

[1] Awad, O. A. \&Suliman, A. A. M. (2011). Range inventory and evaluation of Zalingei area vegetation. Western Darfour State, Sudan. International Journal of sciences and technology (IJSN)., VOL. 2(2): 248-253 ISSN $2229-6441248$

[2] Barnard P, Markus, M.B. (1990). Reproductive failure and nest site selection of two estrildidae finches in Acacia woodland. Ostrich61:117-124.

[3] Campobello D, Sara' M. and Hare, J.F. (2012). Under my wing: lesser kestrels and jackdaws derive reciprocal benefits in mixed-species colonies. BehavEcol 23:425433

[4] Clark RG, Shutler,D. (1999). Avian habitat selection: pattern from process in nest-site use by ducks? Ecology80:272-287

[5] Cody, M. L. (1985). An introduction to habitat selection in birds. Pp. 3-56 in Habitat selection in birds (M. L. Cody, Ed.). Orlando, Florida, Academic Press.

[6] Colin B, Martin J and Stuart M. (1998). Expedition Field Techniques bird surveys. Published by the Expedition Advisory Centre Royal Geographical Society. (with The Institute of British Geographers) Kensington Gore, London SW7 2AR Tel +44 (0)171 591 3030 Fax +44 (0)171 591 3031. Email eac@rgs.org Websitewww.rgs.org. ISBN 0-907649-79-3.

[7] Hilde'n, .0. (1965). Habitat selection in birds. Ann ZoolFenn2:53-75

[8] Hoogland, J. L., \& SHERMAN, P. W. (1976). Advantages and disadvantages of Bank Swallow (Ripariariparia) coloniality. Ecol. Monogr. 46: 33-58.

[9] Horn,H . S. (1968). The adaptive significance of colonial nesting in Brewer's Blackbird (EuphaguscyanocephalusE)c. ology49: 682-694.

[10] Hunting technical serves, April. (1995). Land used planning studies in J, M, R, D, P.(Jebel Marra Rural Development Project .final report, England,p,5

[11] Kelly, J.P.(1993). The effect of nest predation on habitat selection by Dusky Flycatchers in limber pine-juniper woodland. Condor95:83-93

[12] Kleindorfer, S. Sulloway, F.J, and O'Connor, J. (2009). Mixed species nesting associations in Darwin's tree finches: nesting pattern predicts predation outcome. Biol J Linn Soc98:313-324

[13] Kruuk, H . (1964). Predators and anti-predator behavior of the Black-headed Gull (Larusridibundus). Behav. Suppl. II: 1-129.

[14] Lack,R.D. (1968). Ecological adaptations for breeding in birds. London, Methuen.

[15] Lindell, C., R. S. O'Connor, and E. B. Cohen. (2011). Nesting success of Neotropical Thrushes in coffee and pasture. The Wilson Journal of Ornithology 123:502-507.

[16] Lynes, H. (1924-25). On the birds of North and Central Darfour with notes on the West \& Central Kordofan and north Nuba provinces of British Sudan.-Ibis 1924:339446, 648-719; 1925:71-131, 344-416, 541-590, 757-797.

[17] Martin, T. E. (1988a). Are microhabitat preferences of coexisting species under selection and adaptive Ecology79:656-670.

[18] Martin, T. E. (1993). Nest predation and nest sites. BioScience43:523-532.

[19] Mezquida ET, Marone,L. (2002). Microhabitat structure and avian nest predation risk in an open Argentinean woodland: an experimental study. ActaOecol 23:313-320

[20] Nilsson, S. G. (1984). The evolution of nest-site selection among hole-nesting birds: the importance of nest predation and competition. OrnisScandinavica15: 165-175.

[21] Ralph, C. J., G. R. Geupel, P. Pyle, T. E. Martin, D. F. DeSante, and B. Milá. (1996). Manual de métodos de campo para el monitoreo de avesterrestres. U.S. Department of Agriculture, Forest Service, Pacific 


\section{International Journal of Science and Research (IJSR) \\ ISSN (Online): 2319-7064}

Index Copernicus Value (2013): 6.14 | Impact Factor (2015): 6.391

Southwest Research Station, General Technical Report PSW-GTR-159. Albany, CA, USA. [In Spanish.]

[22] Raphael, M. G., \& M. WHITE. (1984). Use of snags by cavity-nesting birds in the Sierra Nevada. Wildl. Monogr. No. 86.

[23] Runde, D. E., \& Capen, D. E. (1987). Characteristics of northern hardwood trees used by cavity-nesting birds. $\underline{\mathrm{J}}$. Wildl. Manage. 5: 217-223.

[24] Scott, V. E. (1978). Characteristics of ponderosa pine snags used by cavity-nesting birds in Arizona. ‥ For. $\underline{76}$ : 26-28.

[25] Tenaza, R. R. (1971). Behavior and nesting success relative to nest location in Adelie Penguins (Pygoscelisadeliae).C ondor73: 81-92.

[26] Wickens, G.E. (1976). The flora of Jebel Marra (Sudan Republic) and its geographical affinities.

[27] Wickens, G.E. (1964).Team Leader and ecologist from Hunting Technical Services Ltd and employed on the United nations Special Fund Jebel Marra Project from the period January to November 1964 and February to July 1965.Based at Zalingei and made numerous collecting tripe throughout the entire project area.

\section{Author Profile}

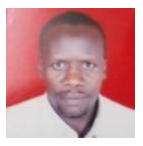

Abdallah. M. A. A. Korssi, He was received the B.Sc. degrees in natural resource and environmental studies from university of Sennar 2005. M.Sc. degrees in Zoology from university of Khartoum 2009. Ph.D. degrees in Zoology (ornithology) from university of Khartoum 2015., He now Registrar of Faculty of Forestry Science, University of Zalingei (2015 to now). Assistant Professor in Wildlife Department, Faculty of Forestry Science, University of Zalingei(2005 to now). He participated in Egyptian vulture studies in February 2013 in Western and Central Darfur States, collaboration with Sudanese Wildlife Society. Also he team leader in study survey for Wildlife Status and distributions in February and June 2014 in Western and Central Darfur States, collaboration with GAFA organization and Land Commission in Regionalauthorityfor Darfur. 